\title{
Truncal Erythema Elevatum Diutinum With Elevated Cryoglobulin Level
}

\author{
Hatice ATAŞ, ${ }^{1}$ Fatma ESKİĞLU, ${ }^{1}$ Hüseyin ÜSTÜN,${ }^{2}$ Müzeyyen GÖNÜL ${ }^{1}$ \\ ${ }^{1}$ Department of Dermatology, Dışkapı Yıldırım Beyazıt Training and Research Hospital, Ankara, Turkey \\ ${ }^{2}$ Department of Pathology, Ankara Training and Research Hospital, Ankara, Turkey
}

Erythema elevatum diutinum (EED) is a rare dermatosis whose prominent clinical and histological features include bilateral and symmetrical papules, nodules and plaques, especially located in a periarticular manner with chronic course and leukocytoclastic vasculitis. ${ }^{1,2}$ Although the etiopathogenesis of EED is unknown, it is thought to be associated with cytokine activation and vascular immuno-complex storage. ${ }^{3,4}$ It may appear idiopathically, as well as alongside autoimmune, hematological, and infectious diseases. In this article, we aim to present a case with truncal EED and elevated cryoglobulin level.

A 35-year-old female patient referred to our dermatology clinic with numerous infiltrated redbrown plaques on her arms, legs, and trunk. Hypo-hyperpigmented areas were also present (Figure 1a, b). We learned that her complaints had continued with remission and recurrences for about 20 years. Leukocytoclastic vasculitis with perivascular localization and polymorphonuclear leukocytes' accumulation in the dermis was detected in the biopsy specimen taken from the active lesion (Figure 1c). No characteristic feature was detected in her own or family history. Diagnosis was established on the basis of clinical and histopathological findings; no infectious focus was detected. Blood count, sedimentation rate, biochemical parameters, protein electrophoresis, levels of immunoglobulin, complement, antistreptolysin $\mathrm{O}, \mathrm{C}$-reactive protein, rheumatoid factor, anti-nuclear antibody, anti-deoxyribonucleic acid levels, tumor markers, and thyroid function tests were all within normal limits. Hepatitis markers, anti-human immunodeficiency virus, and the Venereal Disease Research Laboratory test were negative. Only cryoglobulin positivity was detected. Colchicine treatment was started and a complete response was obtained.

Erythema elevatum diutinum whose deposition of vascular immuno-complex is responsible for the etiopathogenesis is a type of skin disease classified in the group of chronic neutrophilic dermatosis. Histopathologically, it is characterized by a leukocytoclastic vasculitis. ${ }^{5}$ The histopathologic finding of this vasculitis is a distinctive feature of EED from other neutrophilic dermatoses. ${ }^{1}$ Patients usually have multiple, symmetrical, sensitive and violet-colored papules, plaques, and nodules localized around the finger, hand, knee, and elbow joints. Rarely, truncal, retro-auricular, and palmoplantar lesions are reported. ${ }^{6}$ Arm, leg, and truncal involvements were detected in this case.

Erythema elevatum diutinum may be associated with autoimmune diseases such as Celiac disease, Crohn's disease and rheumatoid arthritis, as well as hematological disorders such as myelodysplasia, 

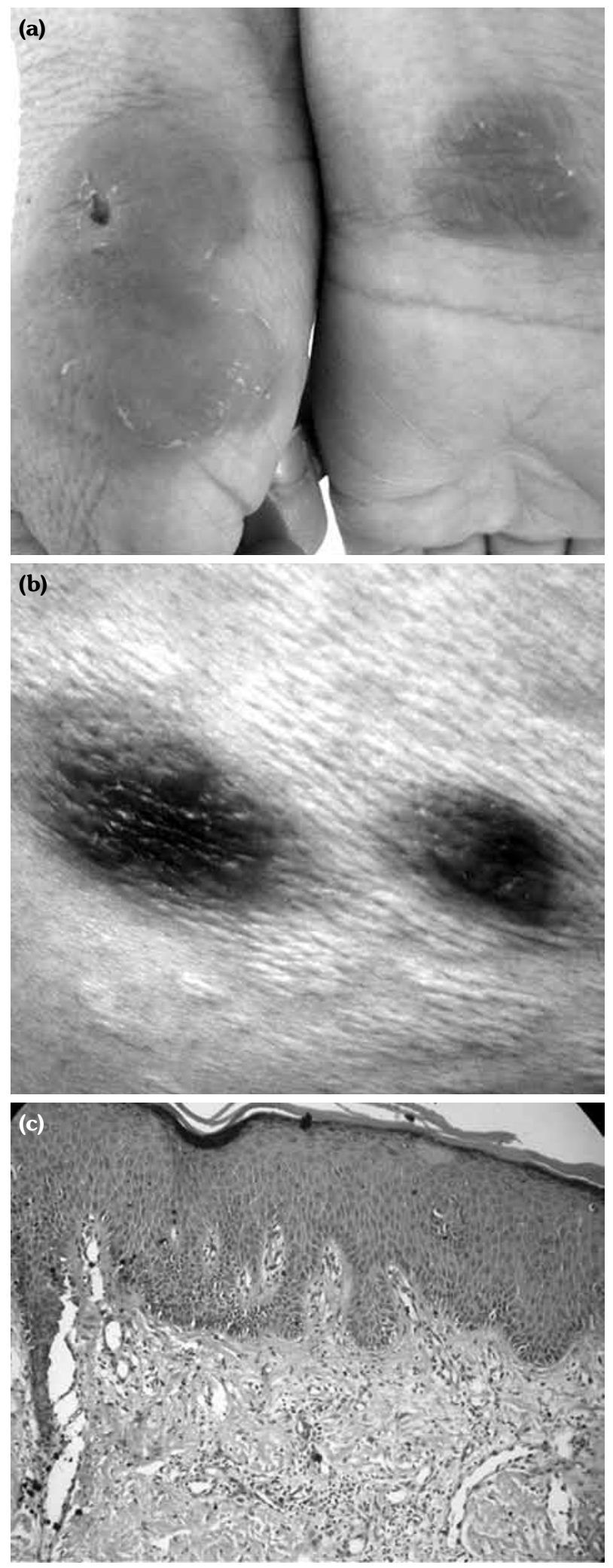

Figure 1. (a) Bilateral, symmetric plaques on wrists. (b) Truncal plaques. (c) Leukocytoclastic vasculitis with perivascular localization and polymorphonuclear leukocytes' accumulation in dermis $(\mathrm{H}-\mathrm{E} \times 200)$. multiple myeloma, immunoglobulin A paraproteinemia, and lymphoma. Cryoglobulin elevation has also been reported.7 Syphilis, human immunodeficiency virus, streptococci, and viral hepatitis have also been pinpointed in the etiology. Cryoglobulin elevation was the only positive finding in this case.

Due to the chronic and recurrent nature of this disease, treatment is highly challenging. The underlying causes should be eliminated first. Dapsone and sulphonamides are the first choice in treatment, with other options including intralesional, topical or oral steroids, niacinamide, tetracycline, colchicine, and chloroquine. ${ }^{6}$ Sometimes, the disease is unresponsive to dapsone, but responsive to colchicine. ${ }^{8}$ In this case, colchicine treatment was selected, and complete response was obtained.

Consequently, we found this rare disease suitable for presentation due to the fact that the plaques placed on the trunk and cryoglobulin positivity were in combination. Colchicine is therefore a successful treatment choice for EED. Protection from cold may also be recommended for these patients.

\section{Declaration of conflicting interests}

The authors declared no conflicts of interest with respect to the authorship and/or publication of this article.

\section{Funding}

The authors received no financial support for the research and/or authorship of this article.

\section{REFERENCES}

1. Yiannias JA, el-Azhary RA, Gibson LE. Erythema elevatum diutinum: a clinical and histopathologic study of 13 patients. J Am Acad Dermatol 1992;26:38-44.

2. Mraz JP, Newcomer VD. Erythema elevatum diutinum. Presentation of a case and evaluation of laboratory and immunological status. Arch Dermatol 1967;96:235-46.

3. Gibson LE, Su WP. Cutaneous vasculitis. Rheum Dis Clin North Am 1990;16:309-24.

4. Farley-Loftus R, Dadlani C, Wang N, Rosenman K, Kamino H, Prystowsky S, et al. Erythema elevatum diutinum. Dermatol Online J 2008;14:13.

5. Ayoub N, Charuel JL, Diemert MC, Barete S, André M, Fermand JP, et al. Antineutrophil cytoplasmic antibodies of IgA class in neutrophilic dermatoses 
with emphasis on erythema elevatum diutinum. Arch Dermatol 2004;140:931-6.

6. Ly H, Black MM. Atypical presentation of erythema elevatum diutinum. Australas J Dermatol 2005;46:44-6.

7. Morrison JG, Hull PR, Fourie E. Erythema elevatum diutinum, cryoglobulinaemia, and fixed urticaria on cooling. Br J Dermatol 1977;97:99-104.

8. Henriksson R, Hofer PA, Hörnquist R. Erythema elevatum diutinum--a case successfully treated with colchicine. Clin Exp Dermatol 1989;14:451-3. 